
\title{
25 Research Soure \\ Lactate Albumin Ratio is Associated with Mortality in Patients with Moderate to Severe Traumatic Brain Injury
}

\section{Ruoran Wang}

Sichuan University West China Hospital

Min $\mathrm{He}$

Sichuan University West China Hospital

\section{Xiaofeng Ou}

Sichuan University West China Hospital

\section{Xiaoqi Xie}

Sichuan University West China Hospital

Yan Kang ( $\nabla$ kangyan@scu.edu.cn )

Sichuan University West China Hospital https://orcid.org/0000-0003-4968-1217

\section{Original research}

Keywords: Traumatic brain injury, lactate, albumin, lactate to albumin ratio, prognosis

Posted Date: July 8th, 2020

DOl: https://doi.org/10.21203/rs.3.rs-37240/v1

License: (c) (1) This work is licensed under a Creative Commons Attribution 4.0 International License. Read Full License

Version of Record: A version of this preprint was published at Frontiers in Neurology on April 1st, 2022. See the published version at https://doi.org/10.3389/fneur.2022.662385. 


\section{Abstract}

Background: Traumatic brain injury (TBI) is a serious public health issue all over the world. This study was designed to evaluate the prognostic value of lactate to albumin ratio (LAR) on moderate to severe traumatic brain injury.

Methods: Clinical data of 273 moderate to severe TBI patients hospitalized in West China Hospital between May 2015 and January 2018 were collected. Multivariate logistic regression analyses were used to explore risk factors and construct prognostic model of in-hospital mortality in this cohort. Nomogram was drawn to visualize the prognostic model. Receiver operating characteristic (ROC) curve and calibration curve were respectively drawn to evaluate discriminative ability and stability of this model.

Results: Non-survivors had higher LAR than survivors ( 1.0870 vs $0.5286, p<0.001)$. Results of multivariate logistic regression analysis showed that GCS (OR=0.818, $p=0.008)$, blood glucose $(O R=1.232, p<0.001)$, LAR (OR=1.883, $p=0.012)$, and red blood cell distribution ( $R D W)-S D(O R=1.179, p=0.004)$ were independent risk factors of in-hospital mortality in included patients. These four factors were utilized to construct prognostic model. The area under the ROC curve (AUC) value of single lactate and LAR were $0.733(95 \% \mathrm{Cl} ; 0.673-0.794)$ and $0.780(95 \% \mathrm{Cl} ; 0.725-0.835)$, respectively. The AUC value of the prognostic model was $0.868(95 \% \mathrm{Cl} ; 0.826-0.909)$, which was higher than that of $\operatorname{LAR}(Z=2.5143, p<0.05)$.

Conclusions: LAR is a readily available prognostic marker of moderate to severe TBI patients.

Prognostic model incorporating LAR is beneficial for clinicians to evaluate possible progression and make treatment decisions in these patients.

\section{Background}

Traumatic brain injury (TBI), defined as an alteration of brain function or other evidence of brain

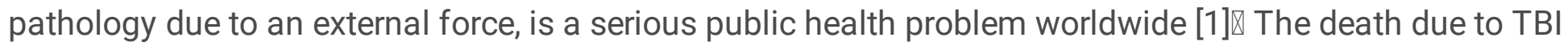
constitutes one-third to one-half of trauma-related death and the disability after TBI is the major cause of all trauma-related disabilities worldwide [2]. Over the past decade, the prognosis of TBI has improved significantly attributable to better implementation of pre-admission treatment, rapid CT examination and high-standard critical care measures [3]. However, the continuously increased incidence rate of TBI makes it still a serious public health issue. Consequently, predicting possible prognosis of patients in early stage and then making suitable treatment strategies is significant to improve outcome of injured patients. The serum lactate level, a widely acknowledged indicator of tissue hypoperfusion, has been confirmed associated with organ failure and mortality in many clinical settings such as sepsis, trauma, pediatric critical Illness [4-8]. And several studies have been conducted to explore the prognostic value of serum lactate level in TBI patients [9-11]. Most of these studies showed that higher serum lactate was associated with worse injury severity and poor outcome in TBI patients. As an important metabolic markers of body, serum lactate level is actually influenced by many factors such as hepatic and renal function. 
In order to stabilize and improve the predictive value of serum lactate, the lactate to albumin ratio (LAR), a new marker which synthetically combine the clinical significance of lactate and albumin is developed and practically tested in several groups of patients [12-14]. Results of these studies showed that LAR might be superior to single lactate in predicting mortality of critically ill patients. And a recent research concluded that the prognostic value of LAR was better than single lactate on predicting neurologic outcome and survival to discharge after out-of-hospital cardiac arrest [15]. Therefore, we make a reasonable assumption that LAR is similarly valuable in predicting mortality of moderate to severe TBI patients. This observational study was designed to verify our scientific hypothesis.

\section{Methods}

\subsection{Patients}

This study was performed in West China hospital. Patients diagnosed with moderate to severe TBI and transferred to our Hospital within 4 hours after injuries between May 2015 and January 2018 were eligible in this study. Diagnoses of TBI were confirmed according to the findings of computed tomography (CT) and magnetic resonance imaging (MRI).

Exclusion criteria were listed as below: (1) patients transferred from other hospital after suffering injuries; (2) patients hospitalized in our hospital less than 48 hours; (3) patients who had intake of alcohol not long before the injury; (4) patients complicated with kidney or liver disease, severe cardiovascular or respiratory diseases, metabolic disease, cancer, malnutrition and other central nervous system diseases; (5) patients lacked in complete laboratory results. A total of 273 patients were finally included in this study. The study was approved by the ethics committee of West China hospital, Sichuan University. Informed consent forms of each patients were legally obtained from themselves or their authorized families.

\subsection{Data collection}

Vital signs and Glasgow Coma Scale (GCS) were recorded once patients admitted to emergency department of our hospital. The blood sample of patients in admission were taken for blood biochemistry, blood routine and arterial gas analysis. Laboratory results of first blood sample on admission were recorded in this study for statistical analysis. The primary outcome of this study was inhospital mortality. The Glasgow Outcome Score (GOS) were evaluated based on patients' survival status and recovery status on 30th day of admission.

\subsection{Statistical analysis}

Kolmogorov-Smirnov test was performed to test the normality of variables. Normally distributed variables were presented as mean \pm standard deviation and non-normally distributed variables were presented as median (interquartile range). And categorical variables were shown as the form of numbers (percentage). Independent Student's t-test and Mann-Whitney $U$ test were respectively performed to analyze differences between two groups of normally distributed and non-normally distributed variables. We performed Chi- 
square test to examine the difference of categorical variables. Univariate and multivariate logistic regression were sequentially used to explore the association between risk factors and mortality in this study cohort. A prognostic nomogram was developed by multivariate logistic regression using the rms package in R project. We draw the receiver operating characteristic (ROC) curves and evaluate predictive value of LAR and the prognostic model by calculating area under the ROC curves (AUC). Finally, stability of the prognostic nomogram was internally validated with 1000 bootstrap samples. Calibration plots were drawn to analyze the consistency between actual probability and predicted probability of poor outcome in the moderate to severe TBI cohort.

A P value $<0.05$ was considered to be of statistical significance. SPSS 22.0 Windows software (SPSS, Inc, Chicago, IL) and R (version 3.6.1; R Foundation) were used for all statistical analysis and figure drawing.

\section{Results}

\subsection{Baseline characteristics of survivors and non-survivors in TBI patients}

There were 124 survivors and 149 non-survivors with a mortality rate of $54.58 \%$ in this study (Table 1.). Age and gender ratio did not differ between survivors and non-survivors ( 43 vs $43, p=0.707 ; 77.4 \%$ vs73.8\%, $p=0.491$ ). Motor vehicle crash and falling injury respectively ranked first and second in the injury cause with $66.3 \%$ and $19.8 \%$. Initial vital signs including systolic and diastolic blood pressure, heart rate did not differ between survivors and non-survivors (123 vs $120, p=0.287 ; 72$ vs $70, p=0.094 ; 98 v$ $103, p=0.184)$. However, the body temperature of non-survivors was significantly lower than survivors (36.7 vs $36.8, p=0.002$ ). And non-survivors had significantly lower GCS than survivors ( 5 vs $7, p<0.001)$. Results of laboratory tests showed that non-survivors had significant higher level of glucose, lactate, LAR, red blood cell distribution (RDW), prothrombin time (PT), lactate dehydrogenase (LDH), total bilirubin (TBil), direct bilirubin (DBil), blood urea nitrogen (BUN) and serum creatinine. Whereas the level of platelet, hemoglobin, albumin was significantly lower in non-survivors group. Compare with survivors, nonsurvivors had shorter length of ICU stay and length of hospital stay $(p<0.001)$. 
Table 1

Baseline characteristics of patients groups divided by survival state

\begin{tabular}{|c|c|c|c|c|}
\hline & $\begin{array}{l}\text { Full cohort }(\mathrm{N}= \\
273)\end{array}$ & $\begin{array}{l}\text { Survivors }(n=124 \text {, } \\
45.42 \%)\end{array}$ & $\begin{array}{l}\text { Non-survivors }(n= \\
149,54.58 \%)\end{array}$ & $\begin{array}{l}\mathrm{P} \\
\text { value }\end{array}$ \\
\hline Age (year) & $43(26-55)$ & $43(24-56)$ & $43(26-55)$ & 0.707 \\
\hline Gender (male) & $206(75.5 \%)$ & $96(77.4 \%)$ & $110(73.8 \%)$ & 0.491 \\
\hline \multicolumn{5}{|l|}{ Mechanism of injury } \\
\hline Motor vehicle crash & $181(66.3 \%)$ & $78(62.9 \%)$ & $103(69.1 \%)$ & 0.279 \\
\hline Fall & $54(19.8 \%)$ & $28(22.6 \%)$ & $26(17.4 \%)$ & 0.290 \\
\hline Stumble & $26(9.5 \%)$ & $11(8.9 \%)$ & $15(10.1 \%)$ & 0.737 \\
\hline Others & $12(4.4 \%)$ & $7(5.6 \%)$ & $5(3.4 \%)$ & 0.359 \\
\hline \multicolumn{5}{|l|}{ Initial vital signs } \\
\hline $\begin{array}{l}\text { Systolic blood pressure } \\
(\mathrm{mmHg})\end{array}$ & $120(106-138)$ & $123(108-138)$ & $120(103-137)$ & 0.287 \\
\hline $\begin{array}{l}\text { Diastolic blood } \\
\text { pressure }(\mathrm{mmHg})\end{array}$ & $71(60-84)$ & $72(65-83)$ & $70(56-84.5)$ & 0.094 \\
\hline Heart rate $(\mathrm{bpm})$ & $101(82-120)$ & $98(81-117)$ & $103(84-123.5)$ & 0.184 \\
\hline Body temperature $\left({ }^{\circ} \mathrm{C}\right)$ & $36.8(36.5-37.1)$ & $36.8(36.5-37.5)$ & $36.7(36.3-37.0)$ & 0.002 \\
\hline GCS in admission & $5(4-7)$ & $7(5-9)$ & $5(4-6)$ & $\begin{array}{l}< \\
0.001\end{array}$ \\
\hline \multicolumn{5}{|l|}{ Laboratory tests } \\
\hline Glucose (mmol/L) & $\begin{array}{l}10.33(7.865- \\
14.29)\end{array}$ & $8.53(6.61-11.59)$ & $12.66(9.16-16.15)$ & $<0.001$ \\
\hline WBC $\left(10^{9} / \mathrm{L}\right)$ & $\begin{array}{l}15.13(11.28- \\
20.06)\end{array}$ & $\begin{array}{l}15.09(11.13- \\
20.08)\end{array}$ & $15.47(11.54-20.14)$ & 0.512 \\
\hline Neutrophil $\left(10^{9} / \mathrm{L}\right)$ & $\begin{array}{l}11.87(8.67- \\
15.24)\end{array}$ & $\begin{array}{l}11.81(8.96- \\
15.43)\end{array}$ & $11.98(7.81-15.12)$ & 0.301 \\
\hline Lymphocyte $\left(10^{9} / \mathrm{L}\right)$ & $0.78(0.53-1.12)$ & $0.88(0.54-1.23)$ & $0.74(0.50-1.04)$ & 0.070 \\
\hline Platelet $\left(10^{9} / \mathrm{L}\right)$ & $90(57-141)$ & $114(76-172)$ & $72(46-112)$ & $\begin{array}{l}< \\
0.001\end{array}$ \\
\hline Hemoglobin (g/L) & $85(73-103)$ & $92(79-110)$ & $81(69-97)$ & $<.001$ \\
\hline Albumin (g/dL) & $3.02(2.61-3.45)$ & $3.25(2.86-3.70)$ & $2.77(2.31-3.18)$ & $<.001$ \\
\hline
\end{tabular}




\begin{tabular}{|c|c|c|c|c|}
\hline & $\begin{array}{l}\text { Full cohort }(\mathrm{N}= \\
273)\end{array}$ & $\begin{array}{l}\text { Survivors }(n=124, \\
45.42 \%)\end{array}$ & $\begin{array}{l}\text { Non-survivors }(n= \\
149,54.58 \%)\end{array}$ & $\begin{array}{l}\mathrm{P} \\
\text { value }\end{array}$ \\
\hline Lactate (mmol/L) & $2.4(1.5-3.6)$ & $1.75(1.2-2.8)$ & $3.1(2.1-4.55)$ & $\begin{array}{l}< \\
0.001\end{array}$ \\
\hline LAR & $\begin{array}{l}0.7809(0.4675- \\
1.3124)\end{array}$ & $\begin{array}{l}0.5286(0.3899- \\
0.7918)\end{array}$ & $\begin{array}{l}1.0870(0.7253- \\
1.7195)\end{array}$ & $\begin{array}{l}<.001 \\
0.001\end{array}$ \\
\hline RDW-CV (\%CV) & $14.6(13.5-15.5)$ & $13.7(13.1-14.9)$ & $14.9(14.3-16)$ & $\begin{array}{l}<.001 \\
0.001\end{array}$ \\
\hline RDW-SD (fL) & $47.1(43.4-51.2)$ & $44.45(41.6-48.8)$ & $49.5(46.0-53.4)$ & $\begin{array}{l}< \\
0.001\end{array}$ \\
\hline PT (s) & $13.9(12.5-16.3)$ & $13.0(11.9-14.6)$ & $15.1(13.4-18.2)$ & $\begin{array}{l}< \\
0.001\end{array}$ \\
\hline LDH & $400(301-594)$ & $360(289-479)$ & $452(330-775)$ & $\begin{array}{l}< \\
0.001\end{array}$ \\
\hline ALP & $69(47-98)$ & $65(45-91)$ & $73(51-101)$ & 0.205 \\
\hline TBil (umol/L) & $16.4(11.1-21.6)$ & $14.3(10.6-19.8)$ & $17.9(11.8-22.6)$ & 0.006 \\
\hline DBil (umol/L) & $7.7(5.4-10.9)$ & $6.6(4.4-8.9)$ & $8.3(6-12)$ & ¿ 0.001 \\
\hline BUN & $6.34(4.81-8.82)$ & $5.72(4.36-7.69)$ & $7.11(5.35-9.91)$ & $\begin{array}{l}< \\
0.001\end{array}$ \\
\hline Serum creatinine & $76(56-106)$ & $65(54-85)$ & $84(59-124)$ & $\begin{array}{l}< \\
0.001\end{array}$ \\
\hline GOS & $1(1-3)$ & $3(2-3)$ & $1(1-1)$ & $\dot{0} 001$ \\
\hline $\begin{array}{l}\text { Length of ICU stay } \\
\text { (day) }\end{array}$ & $10(2-24)$ & $21(13-33)$ & $2(1-7)$ & $\begin{array}{l}< \\
0.001\end{array}$ \\
\hline $\begin{array}{l}\text { Length of hospital stay } \\
\text { (day) }\end{array}$ & $15(5-34)$ & $31(22-48)$ & $5(3-12)$ & $\begin{array}{l}< \\
0.001\end{array}$ \\
\hline \multicolumn{5}{|c|}{$\begin{array}{l}\text { GCS Glasgow Coma Scale; WBC White blood cell; LAR Lactate to albumin ratio; RDW Red blood cell } \\
\text { distribution width; PT Prothrombin time; LDH Lactate dehydrogenase; ALP Alkaline phosphatase; TBi } \\
\text { total bilirubin; DBi, direct bilirubin; BUN blood urea nitrogen; GOS Glasgow Outcome Scale. }\end{array}$} \\
\hline
\end{tabular}

In univariate logistic regression analysis, we found that body temperature $(O R=0.670, p=0.004), G C S$ $(O R=0.732, p<0.001)$, platelet $(O R=0.993, p<0.001)$, hemoglobin $(O R=0.978, p<0.001)$ were positively correlated with outcome in TBI patients (Table 2.). And glucose $(p<0.001)$, LAR $(p<0.001)$, CV $(p<0.001)$, SD $(p<0.001)$, PT $(p<0.001), \operatorname{LDH}(p<0.001)$, TBil $(p=0.044)$, DBil $(p=0.012)$, BUN $(p=0.030)$, serum creatinine $(p=0.003)$ were risk factors of mortality in the TBI patients. Furthermore, results of multivariate 
logistic regression analysis indicated that only GCS $(O R=0.818, p=0.008)$, glucose $(O R=1.232, p<$ $0.001)$, $\operatorname{LAR}(O R=1.883, p=0.012)$ and $S D(O R=1.179, p=0.004)$ were independently associated with mortality after adjusting confounders. 
Table 2

Univariate and multivariate logistic regression analysis of risk factors for mortality in patients with moderate to severe TBI

\begin{tabular}{|c|c|c|c|c|}
\hline & \multicolumn{2}{|c|}{ Unadjusted analysis } & \multicolumn{2}{|l|}{ Adjusted analysis } \\
\hline & OR $(95 \% \mathrm{Cl})$ & $\begin{array}{l}P \\
\text { value }\end{array}$ & OR $(95 \% \mathrm{Cl})$ & $P$ value \\
\hline Age (year) & $\begin{array}{l}1.003(0.990- \\
1.015)\end{array}$ & 0.683 & $0.986(0.965-1.008)$ & 0.204 \\
\hline Gender (male) & $\begin{array}{l}0.823(0.471- \\
1.436)\end{array}$ & 0.492 & $1.256(0.528-2.987)$ & 0.606 \\
\hline Systolic blood pressure & $\begin{array}{l}1.001(0.997- \\
1.005)\end{array}$ & 0.636 & $1.016(0.996-1.037)$ & 0.115 \\
\hline $\begin{array}{l}\text { Diastolic blood } \\
\text { pressure }\end{array}$ & $\begin{array}{l}0.987(0.973- \\
1.001)\end{array}$ & 0.077 & $0.972(0.942-1.003)$ & 0.079 \\
\hline Heart rate & $\begin{array}{l}1.006(0.997- \\
1.014)\end{array}$ & 0.176 & $1.001(0.988-1.015)$ & 0.872 \\
\hline Body temperature & $\begin{array}{l}0.670(0.511- \\
0.878)\end{array}$ & 0.004 & $0.667(0.436-1.020)$ & 0.062 \\
\hline GCS in admission & $\begin{array}{l}0.732(0.650- \\
0.824)\end{array}$ & $<0.001$ & $0.818(0.705-0.950)$ & 0.008 \\
\hline Glucose & $\begin{array}{l}1.275(1.182- \\
1.374)\end{array}$ & $<0.001$ & $1.232(1.103-1.376)$ & $<0.001$ \\
\hline WBC & $\begin{array}{l}1.013(0.979- \\
1.048)\end{array}$ & 0.458 & $1.003(0.931-1.081)$ & 0.939 \\
\hline Neutrophil & $\begin{array}{l}0.982(0.942- \\
1.024)\end{array}$ & 0.399 & $0.962(0.879-1.053)$ & 0.398 \\
\hline Lymphocyte & $\begin{array}{l}0.680(0.454- \\
1.021)\end{array}$ & 0.063 & $0.526(0.253-1.091)$ & 0.084 \\
\hline Platelet & $\begin{array}{l}0.993(0.990- \\
0.997)\end{array}$ & $<0.001$ & $1.002(0.997-1.007)$ & 0.420 \\
\hline Hemoglobin & $\begin{array}{l}0.978(0.967- \\
0.990)\end{array}$ & $<0.001$ & $1.004(0.986-1.022)$ & 0.684 \\
\hline LAR & $\begin{array}{l}3.611(2.219- \\
5.876)\end{array}$ & $<0.001$ & $1.883(1.152-3.077)$ & 0.012 \\
\hline RDW-CV & $\begin{array}{l}1.680(1.382- \\
2.043)\end{array}$ & $<0.001$ & $0.964(0.661-1.404)$ & 0.847 \\
\hline RDW-SD & $\begin{array}{l}1.162(1.104- \\
1.222)\end{array}$ & $<0.001$ & $1.179(1.055-1.319)$ & 0.004 \\
\hline
\end{tabular}




\begin{tabular}{|c|c|c|c|c|}
\hline \multirow[b]{2}{*}{ PT } & \multicolumn{2}{|c|}{ Unadjusted analysis } & \multicolumn{2}{|l|}{ Adjusted analysis } \\
\hline & $\begin{array}{l}1.292(1.168- \\
1.429)\end{array}$ & $<0.001$ & $1.146(0.982-1.339)$ & 0.084 \\
\hline LDH & $\begin{array}{l}1.002(1.001- \\
1.003)\end{array}$ & $<0.001$ & $1.001(1.000-1.002)$ & 0.206 \\
\hline ALP & $\begin{array}{l}1.002(0.997- \\
1.006)\end{array}$ & 0.403 & $1.004(0.995-1.014)$ & 0.347 \\
\hline TBil & $\begin{array}{l}1.029(1.001- \\
1.058)\end{array}$ & 0.044 & $1.024(0.957-1.097)$ & 0.491 \\
\hline DBil & $\begin{array}{l}1.071(1.015- \\
1.130)\end{array}$ & 0.012 & $0.994(0.883-1.120)$ & 0.925 \\
\hline BUN & $\begin{array}{l}1.068(1.006- \\
1.133)\end{array}$ & 0.030 & $1.027(0.942-1.120)$ & 0.544 \\
\hline Serum creatinine & $\begin{array}{l}1.007(1.002- \\
1.011)\end{array}$ & 0.003 & $0.999(0.991-1.007)$ & 0.777 \\
\hline
\end{tabular}

\subsection{Predictive value of LAR and constructed prognostic model}

Combing GCS, glucose, LAR and SD, we constructed prognostic model for predicting mortality in the TBI patients by multivariate logistic regression analysis. Nomogram was drawn for visualization and convenient clinical use of this prognostic model (Fig. 2A). The AUC value of GCS and single lactate value were $0.718(95 \% \mathrm{Cl} ; 0.657-0.780)$ and $0.733(95 \% \mathrm{Cl} ; 0.673-0.794)$, respectively (Table 3.). The AUC value of LAR and the prognostic model was 0.780 (95\% Cl; 0.725-0.835) and $0.868(95 \% \mathrm{Cl} ; 0.826-0.909)$, respectively. The AUC value of LAR was significantly higher than that of GCS $(Z=1.4842, p>0.05)$ and single lactate value $(Z=1.1251, p>0.05)$ though without statistical significance. However, the prognostic model incorporating LAR had significant higher AUC value than single LAR $(Z=2.5143, p<0.05)$. In addition, the calibration plot of this prognostic model showed a good consistency between the prediction by nomogram and actual observation (Fig. 2B). 
Table 3

Predictive value of significant factors and prognostic model on mortality in patients with moderate to severe TBI

\begin{tabular}{|lcccc|}
\hline Predictive factors & AUC & $\mathbf{9 5 \%} \mathbf{C l}$ & Sensitivity & Specificity \\
\hline GCS & 0.718 & $0.657-0.780$ & 0.532 & 0.805 \\
\hline Lactate & 0.733 & $0.673-0.794$ & 0.725 & 0.653 \\
\hline LAR & 0.780 & $0.725-0.835$ & 0.678 & 0.798 \\
\hline Prognostic model & 0.868 & $0.826-0.909$ & 0.926 & 0.637 \\
$\begin{array}{l}\text { TBI Traumatic brain injury; GCS Glasgow Coma Scale; LAR Lactate to albumin ratio; AUC Area under } \\
\text { the ROC curve; Cl Confidence interval. }\end{array}$ & \\
The prognostic model is composed of GCS, glucose, LAR and RDW-SD. & \\
\hline
\end{tabular}

\section{Discussion}

Several researches have confirmed that LAR is associated with mortality and the development of multiple organ dysfunction syndrome (MODS) in generalized or pediatric sepsis patients $[12-14,16,17]$. A recent study showed that LAR had higher value than single lactate level on predicting neurologic outcomes and survival to discharge in patients suffering out-of-hospital cardiac arrest [15]. We make a reasonable hypothesis that LAR would also be superior to single lactate in predicting mortality in TBI patients.

As a component of LAR, the serum lactate is widely acknowledged as an indicator of inadequate tissue perfusion. And the correlation between serum lactate and mortality has been verified in many clinical settings such as sepsis, shock and trauma [18-21]. However, several studies exploring the association between lactate and outcome in TBI patients showed different conclusions [22-25]. One of these studies even indicated that TBI patients whose serum lactate $>5 \mathrm{mmol} / \mathrm{L}$ were likely to have a better survival than those with relatively low lactate level [24]. Furthermore, exogenous supplement of lactate by infusing hypertonic sodium lactate has been verified beneficial for survival and neurologic outcome and cognitive recovery in TBI animal models and patients [26-32]. In our study, serum lactate was higher in nonsurvivors than survivors, and was useful in predicting mortality in moderate to severe TBI patients with AUC of 0.733 . The most key point we think to understand and discuss the relationship between blood lactate and outcome of TBI patients is the different meaning of increased serum lactate between the initial pathophysiological state and exogenous supplement state.

A previous study found that serum lactate would still increase even in normotensive TBI patients [24]. This fact indicated initial increase of serum lactate after TBI could not only caused by peripheral tissue hypoperfusion due to blood loss, but also the worsening tissue oxygenation due to complications such as acute lung injury and neurogenic lung edema. The detailed mechanism of initial increased lactate after TBI deserves further exploration. Initially put forward in 1994, the astrocyte-neuron lactate shuttle has 
changed the opinion that lactate is only an useless waste during anaerobic metabolism process [33]. It was illustrated that astrocyte would uptake glucose and metabolized it into lactate under the stimulation of much glutamate. Those generated lactate would be transferred to neurons and enter the tricarboxylic acid cycle for energy demand of brain. The increased serum lactate directly penetrating the blood-brainbarrier would also accumulate in neuronal intercellular space and utilized by neurons for energy production $[34,35]$. And one study discovered that brain uptake of lactate reflecting by arterio-venous differences for lactate (AVDlac) was higher in more severe TBI patients and non-survivors [36]. Therefore, a reasonable conjecture is that uptake of lactate from neuron after more severe TBI would decrease more serum level of lactate. However, it was confirmed that the magnitude of absorbed lactate by brain was extremely small compared with magnitude of serum lactate level [36]. Therefore, the initial fluctuation of serum lactate level after TBI is mainly attributable to pathophysiological changes of systemic body but not of single brain. This argument might be confirmed by the finding of previous study that blood lactate levels was associated with Sequential Organ Failure Assessment (SOFA) score which reflects systemic organ failure in unspecified ICU patients [37]. In addition, blood lactate level was also verified inversely associated with Glasgow Coma Scale (GCS) in isolated TBI patients [24]. Although higher serum lactate is beneficial for brain energy supplement, the effect of poor pathophysiologic condition indicated by higher serum lactate on outcome could be greater than relatively transient and small effect of energy supplement. Generally, the initial increased serum lactate in natural pathophysiologic condition is inversely associated with favorable outcome in TBI patients by reflecting degree of systemic organ failure and initial brain injury severity.

On the contrary, the continuously increased serum lactate level during exogenous infusion of hypertonic sodium lactate could indicate better survival and recovery after TBI[30, 38, 39]. Because increased serum lactate during exogenous supplement is not a reflection of initial tissue hypoperfusion and organ failure, but only means more alternative energy fuel for injured brain. This is a key point to distinguish the meaning of increased serum lactate under the initial pathophysiological condition and exogenous supplement condition. The beneficial effects of hypertonic sodium lactate on injured brain has been definitely recognized including improving cerebral perfusion and brain glucose availability, reversing impaired brain metabolism and oxygenation, etc. [26-28]. In addition to the function of neuroenergetic material, lactate is actually a crucial signaling molecule which could modulate the production of pentose phosphate, an important molecule to prevent oxidative stress injury in brain [40-43]. It was testified that lactate would provide $60 \%$ of the energy source for cerebral metabolism as blood lactate increases to $5 \mathrm{mmol} / \mathrm{L}[44,45]$, To sum up, the elevated serum lactate level during exogenous supplement of lactate is beneficial for neurologic and survival outcome, and cognitive recovery after TBI.

The albumin level of non-survivors was significantly lower than survivors in this study. Produced by hepatocytes, albumin works in multiple way to maintain physiologic function of healthy body including constituting plasma osmotic pressure, transporting insoluble small organic molecules and combining heavy metal ions to eliminate their toxic effects. And low albumin level is also considered as an efficient marker of malnutrition. The causes of hypoalbuminemia after TBI is diversified including initial blood loss due to injury, consumption by secondary oxidative stress injury and physiological hypoalbuminemia 
resulted from massive crystal liquid infusion. The reduction of serum albumin and its association with mortality after TBI have been confirmed in previous studies [46-49]. The correlation between hypoalbuminemia and poor outcome of TBI patients could be explained by the brain edema and subsequent increased intracranial pressure resulted from insufficient intravascular osmolality. In addition, lower level of albumin could indicate more severe degree of systemic inflammatory response, which was discovered correlated with poor outcome of TBI patients [50,51]. In our study, the AUC value of single lactate was 0.733 . After the incorporation of albumin, the AUC value of LAR was elevated to 0.780 . This result indicated that LAR, calculated by the value of lactate and albumin, could more comprehensively reflect tissue injury severity and systemic organ function of TBI patients. The prognostic model constructed by us, which consisted of GCS, glucose, LAR and RDW, is useful in predicting mortality of moderate to severe TBI patients with high discriminative ability and sensitivity.

This study had several limitations. Firstly, this observational study was performed in a single center so that the selection bias was inevitable. A further prospective study with larger sample size in other centers should be conducted to externally validate the predictive value of our prognostic model. Secondly, the long-term neurologic outcome and recovery status were not followed up and recorded so that we could not explore the correlation between LAR and them. Thirdly, the drugs and operations of prehospital emergency medical care which could influence the serum lactate level were not recorded by us. Our results might be confounded by these factors.

\section{Conclusion}

The LAR is an effective and readily available indicator of brain injury severity and outcome in moderate to severe TBI patients. The prognostic model incorporating LAR with high predictive value is beneficial for clinicians to evaluate possible progression and adjust treatment decisions in moderate to severe TBI patients.

\section{Declarations}

\section{Acknowledgements}

None.

\section{Authors' contributions}

RRW performed the study design, article's drafting; MH performed statistical analysis; XFO and XQX collected data; YK reviewed and approved the final version of this study.

\section{Funding}


This study was funded by 1.3.5 project for disciplines of excellence, West China Hospital, Sichuan University.

\section{Availability of data and materials}

The datasets used and/or analyzed during the current study are available from the corresponding author on reasonable request.

\section{Ethics approval and consent to participate}

The studies involving human participants were reviewed and approved by the ethics committee of West China hospital, Sichuan University. Informed consents of each patients were obtained by us.

\section{Consent for publication}

Not applicable.

\section{Competing interests}

The authors declared that they have competing interests to disclose.

\section{References}

1. Menon DK, Schwab K, Wright DW, Maas Al. Position statement: definition of traumatic brain injury. Archives of physical medicine and rehabilitation. 2010;91(11):1637-40.

2. Iaccarino C, Carretta A, Nicolosi F, Morselli C. Epidemiology of severe traumatic brain injury. Journal of neurosurgical sciences. 2018;62(5):535-41.

3. Lu J, Marmarou A, Choi S, Maas A, Murray G, Steyerberg EW. Mortality from traumatic brain injury. Acta neurochirurgica Supplement. 2005;95:281-5.

4. Thanachartwet V, Desakorn V, Sahassananda D, Jittmittraphap A, Oer-Areemitr N, Osothsomboon S, et al. Serum Procalcitonin and Peripheral Venous Lactate for Predicting Dengue Shock and/or Organ Failure: A Prospective Observational Study. PLoS neglected tropical diseases. 2016;10(8):e0004961.

5. Sobhian B, Kröpfl A, Hölzenbein T, Khadem A, Redl H, Bahrami S. Increased circulating D-lactate levels predict risk of mortality after hemorrhage and surgical trauma in baboons. Shock (Augusta, Ga). 2012;37(5):473-7.

6. Mikkelsen ME, Miltiades AN, Gaieski DF, Goyal M, Fuchs BD, Shah CV, et al. Serum lactate is associated with mortality in severe sepsis independent of organ failure and shock. Critical care medicine. 2009;37(5):1670-7. 
7. Guyette F, Suffoletto B, Castillo JL, Quintero J, Callaway C, Puyana JC. Prehospital serum lactate as a predictor of outcomes in trauma patients: a retrospective observational study. The Journal of trauma. 2011;70(4):782-6.

8. Bai Z, Zhu X, Li M, Hua J, Li Y, Pan J, et al. Effectiveness of predicting in-hospital mortality in critically ill children by assessing blood lactate levels at admission. BMC pediatrics. 2014;14:83.

9. Stefani MA, Modkovski R, Hansel G, Zimmer ER, Kopczynski A, Muller AP, et al. Elevated glutamate and lactate predict brain death after severe head trauma. Annals of clinical and translational neurology. 2017;4(6):392-402.

10. Fu YQ, Bai K, Liu CJ. The impact of admission serum lactate on children with moderate to severe traumatic brain injury. PloS one. 2019;14(9):e0222591.

11. Dübendorfer C, Billeter AT, Seifert B, Keel M, Turina M. Serial lactate and admission SOFA scores in trauma: an analysis of predictive value in 724 patients with and without traumatic brain injury. European journal of trauma and emergency surgery : official publication of the European Trauma Society. 2013;39(1):25-34.

12. Shin J, Hwang SY, Jo IJ, Kim WY, Ryoo SM, Kang GH, et al. Prognostic Value of The Lactate/Albumin Ratio for Predicting 28-Day Mortality in Critically ILL Sepsis Patients. Shock (Augusta, Ga). 2018;50(5):545-50.

13. Wang B, Chen G, Cao Y, Xue J, Li J, Wu Y. Correlation of lactate/albumin ratio level to organ failure and mortality in severe sepsis and septic shock. Journal of critical care. 2015;30(2):271-5.

14. Lichtenauer M, Wernly B, Ohnewein B, Franz M, Kabisch B, Muessig J, et al. The Lactate/Albumin Ratio: A Valuable Tool for Risk Stratification in Septic Patients Admitted to ICU. International journal of molecular sciences. 2017;18(9).

15. Kong T, Chung SP, Lee HS, Kim S, Lee J, Hwang SO, et al. The Prognostic Usefulness of the Lactate/Albumin Ratio for Predicting Clinical Outcomes in Out-of-Hospital Cardiac Arrest: a Prospective, Multicenter Observational Study (koCARC) Study. Shock (Augusta, Ga). 2020;53(4):44251.

16. Choi SJ, Ha EJ, Jhang WK, Park SJ. Association between the lactate/albumin ratio and mortality in pediatric septic shock patients with underlying chronic disease: retrospective pilot study. Minerva pediatrica. 2016.

17. Moustafa AA, Antonios MA, Abdellatif EM, Hussain AH. Association of lactate/albumin ratio level to organ failure and mortality in severe sepsis in a pediatric intensive care unit in Egypt. Turk J Pediatr. 2018;60(6):691-701.

18. Ryoo SM, Lee J, Lee Y-S, Lee JH, Lim KS, Huh JW, et al. Lactate Level Versus Lactate Clearance for Predicting Mortality in Patients With Septic Shock Defined by Sepsis-3. Critical care medicine. 2018;46(6):e489-e95.

19. Haas SA, Lange T, Saugel B, Petzoldt M, Fuhrmann V, Metschke M, et al. Severe hyperlactatemia, lactate clearance and mortality in unselected critically ill patients. Intensive care medicine. 2016;42(2):202-10. 
20. Raux M, Le Manach Y, Gauss T, Baumgarten R, Hamada S, Harrois A, et al. Comparison of the Prognostic Significance of Initial Blood Lactate and Base Deficit in Trauma Patients. Anesthesiology. 2017;126(3):522-33.

21. Johnson MC, Alarhayem A, Convertino V, Carter R, Chung K, Stewart R, et al. Comparison of compensatory reserve and arterial lactate as markers of shock and resuscitation. The journal of trauma and acute care surgery. 2017;83(4):603-8.

22. Fu Y-Q, Bai K, Liu C-J. The impact of admission serum lactate on children with moderate to severe traumatic brain injury. PloS one. 2019;14(9):e0222591.

23. Dekker SE, de Vries HM, Lubbers WD, van de Ven PM, Toor EJ, Bloemers FW, et al. Lactate clearance metrics are not superior to initial lactate in predicting mortality in trauma. European journal of trauma and emergency surgery : official publication of the European Trauma Society. 2017;43(6):841-51.

24. Cureton EL, Kwan RO, Dozier KC, Sadjadi J, Pal JD, Victorino GP. A different view of lactate in trauma patients: protecting the injured brain. The Journal of surgical research. 2010;159(1):468-73.

25. Zehtabchi S, Sinert R, Soghoian S, Liu Y, Carmody K, Shah L, et al. Identifying traumatic brain injury in patients with isolated head trauma: are arterial lactate and base deficit as helpful as in polytrauma? Emergency medicine journal : EMJ. 2007;24(5):333-5.

26. Arifianto MR, Ma'ruf AZ, Ibrahim A, Bajamal AH. Role of Hypertonic Sodium Lactate in Traumatic Brain Injury Management. Asian journal of neurosurgery. 2018;13(4):971-5.

27. Carteron L, Solari D, Patet C, Quintard H, Miroz JP, Bloch J, et al. Hypertonic Lactate to Improve Cerebral Perfusion and Glucose Availability After Acute Brain Injury. Critical care medicine. 2018;46(10):1649-55.

28. Millet A, Cuisinier A, Bouzat P, Batandier C, Lemasson B, Stupar V, et al. Hypertonic sodium lactate reverses brain oxygenation and metabolism dysfunction after traumatic brain injury. British journal of anaesthesia. 2018;120(6):1295-303.

29. Bouzat P, Sala N, Suys T, Zerlauth J-B, Marques-Vidal P, Feihl F, et al. Cerebral metabolic effects of exogenous lactate supplementation on the injured human brain. Intensive care medicine. 2014;40(3):412-21.

30. Mannino C, Glenn TC, Hovda DA, Vespa PM, McArthur DL, Van Horn JD, et al. Acute glucose and lactate metabolism are associated with cognitive recovery following traumatic brain injury. Journal of neuroscience research. 2018;96(4):696-701.

31. Rice AC, Zsoldos R, Chen T, Wilson MS, Alessandri B, Hamm RJ, et al. Lactate administration attenuates cognitive deficits following traumatic brain injury. Brain research. 2002;928(1-2):156-9.

32. Alessandri B, Schwandt E, Kamada Y, Nagata M, Heimann A, Kempski O. The neuroprotective effect of lactate is not due to improved glutamate uptake after controlled cortical impact in rats. Journal of neurotrauma. 2012;29(12):2181-91.

33. Pellerin L, Magistretti PJ. Glutamate uptake into astrocytes stimulates aerobic glycolysis: a mechanism coupling neuronal activity to glucose utilization. Proceedings of the National Academy 
of Sciences of the United States of America. 1994;91(22):10625-9.

34. Simpson IA, Carruthers A, Vannucci SJ. Supply and demand in cerebral energy metabolism: the role of nutrient transporters. Journal of cerebral blood flow and metabolism : official journal of the International Society of Cerebral Blood Flow and Metabolism. 2007;27(11):1766-91.

35. Chen T, Qian YZ, Di X, Zhu JP, Bullock R. Evidence for lactate uptake after rat fluid percussion brain injury. Acta neurochirurgica Supplement. 2000;76:359-64.

36. Glenn TC, Kelly DF, Boscardin WJ, McArthur DL, Vespa P, Oertel M, et al. Energy dysfunction as a predictor of outcome after moderate or severe head injury: indices of oxygen, glucose, and lactate metabolism. Journal of cerebral blood flow and metabolism : official journal of the International Society of Cerebral Blood Flow and Metabolism. 2003;23(10):1239-50.

37. Jansen TC, van Bommel J, Woodward R, Mulder PGH, Bakker J. Association between blood lactate levels, Sequential Organ Failure Assessment subscores, and 28-day mortality during early and late intensive care unit stay: a retrospective observational study. Critical care medicine. 2009;37(8):236974.

38. Ichai C, Armando G, Orban J-C, Berthier F, Rami L, Samat-Long C, et al. Sodium lactate versus mannitol in the treatment of intracranial hypertensive episodes in severe traumatic brain-injured patients. Intensive care medicine. 2009;35(3):471-9.

39. Bisri T, Utomo BA, Fuadi I. Exogenous lactate infusion improved neurocognitive function of patients with mild traumatic brain injury. Asian journal of neurosurgery. 2016;11(2):151-9.

40. Dusick JR, Glenn TC, Lee WNP, Vespa PM, Kelly DF, Lee SM, et al. Increased pentose phosphate pathway flux after clinical traumatic brain injury: a [1,2-13C2]glucose labeling study in humans. Journal of cerebral blood flow and metabolism : official journal of the International Society of Cerebral Blood Flow and Metabolism. 2007;27(9):1593-602.

41. Mosienko V, Teschemacher AG, Kasparov S. Is L-lactate a novel signaling molecule in the brain? Journal of cerebral blood flow and metabolism : official journal of the International Society of Cerebral Blood Flow and Metabolism. 2015;35(7):1069-75.

42. Castillo X, Rosafio K, Wyss MT, Drandarov K, Buck A, Pellerin L, et al. A probable dual mode of action for both L- and D-lactate neuroprotection in cerebral ischemia. Journal of cerebral blood flow and metabolism : official journal of the International Society of Cerebral Blood Flow and Metabolism. 2015;35(10):1561-9.

43. Sotelo-Hitschfeld T, Niemeyer MI, Mächler P, Ruminot I, Lerchundi R, Wyss MT, et al. Channel-

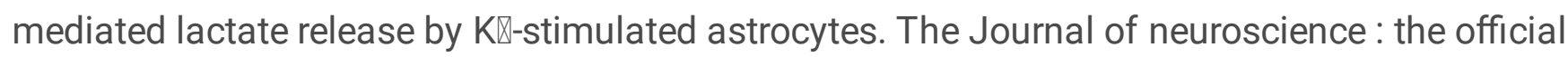
journal of the Society for Neuroscience. 2015;35(10):4168-78.

44. Boumezbeur F, Petersen KF, Cline GW, Mason GF, Behar KL, Shulman GI, et al. The contribution of blood lactate to brain energy metabolism in humans measured by dynamic 13C nuclear magnetic resonance spectroscopy. The Journal of neuroscience : the official journal of the Society for Neuroscience. 2010;30(42):13983-91. 
45. Quistorff B, Secher NH, Van Lieshout JJ. Lactate fuels the human brain during exercise. FASEB journal : official publication of the Federation of American Societies for Experimental Biology. 2008;22(10):3443-9.

46. Montalcini T, Moraca M, Ferro Y, Romeo S, Serra S, Raso MG, et al. Nutritional parameters predicting pressure ulcers and short-term mortality in patients with minimal conscious state as a result of traumatic and non-traumatic acquired brain injury. Journal of translational medicine. 2015;13:305.

47. Chen D, Bao L, Lu SQ, Xu F. Serum albumin and prealbumin predict the poor outcome of traumatic brain injury. PloS one. 2014;9(3):e93167.

48. Luo HC, Fu YQ, You CY, Liu CJ, Xu F. Comparison of admission serum albumin and hemoglobin as predictors of outcome in children with moderate to severe traumatic brain injury: A retrospective study. Medicine. 2019;98(44):e17806.

49. Baltazar GA, Pate AJ, Panigrahi B, LaBoy S, Prosniak R, Mody A, et al. Malnutrition as measured by albumin and prealbumin on admission is associated with poor outcomes after severe traumatic brain injury. The American surgeon. 2015;81(2):E61-3.

50. Esper DH, Harb WA. The cancer cachexia syndrome: a review of metabolic and clinical manifestations. Nutrition in clinical practice : official publication of the American Society for Parenteral and Enteral Nutrition. 2005;20(4):369-76.

51. Jacome T, Tatum D. Systemic Inflammatory Response Syndrome (SIRS) Score Independently Predicts Poor Outcome in Isolated Traumatic Brain Injury. Neurocritical care. 2018;28(1):110-6.

\section{Figures}

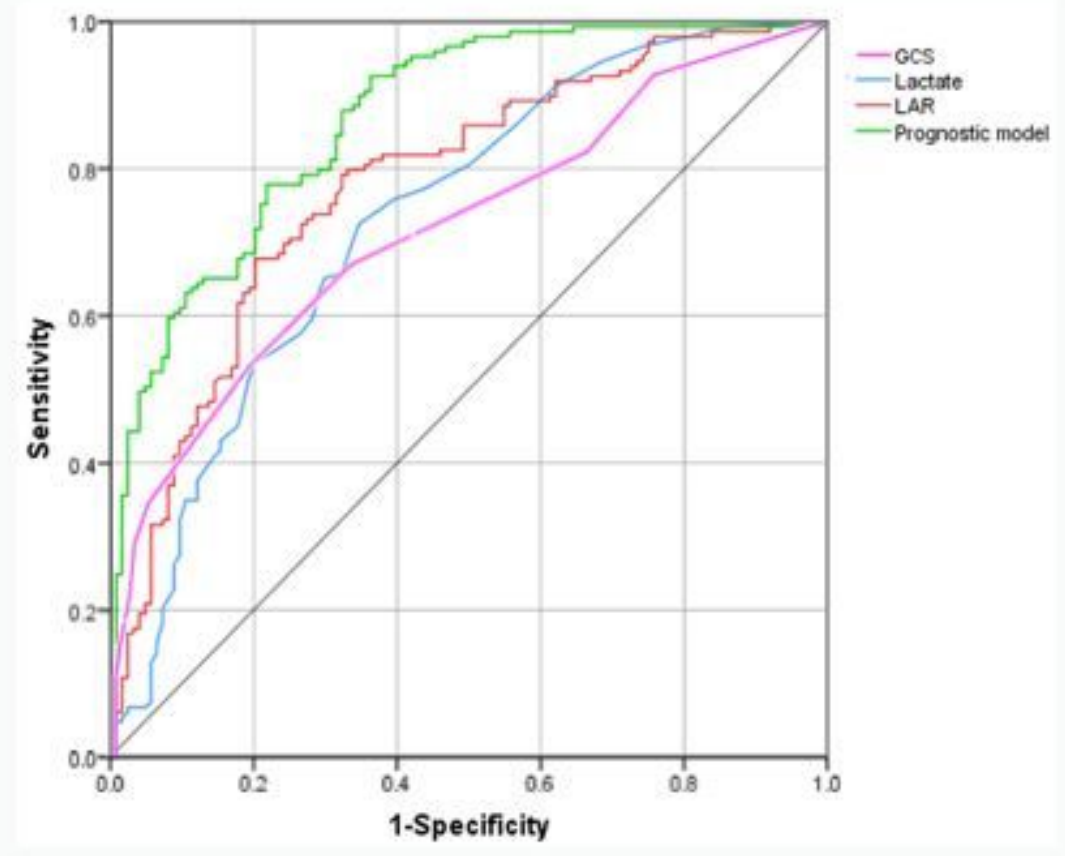

Figure 1 
ROC curves of significant factors and the prognostic model for mortality in moderate to severe TBI patients.

Points

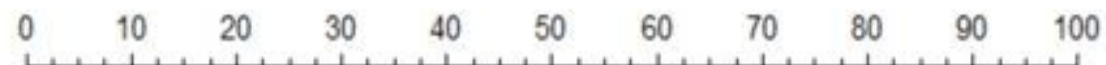

GCS

Glucose

LAR

RDW-SD

Total Points

Linear Predictor

Mortality

\begin{tabular}{cccccccccc}
\hline 15 & 13 & 11 & 9 & 7 & 5 & 3 & & \\
\cline { 3 - 3 } & 1 & 1 & 1 & 1 & 1 & 1 & \\
\hline 0 & 5 & 10 & 15 & 20 & 25 & 30 & 35
\end{tabular}

\begin{tabular}{llllllllll}
\hline 0 & 2 & 4 & 6 & 8 & 10 & 12 & 14 & 16 & 18
\end{tabular}

\begin{tabular}{llllllllllll}
\hline 30 & 35 & 40 & 45 & 50 & 55 & 60 & 65 & 70 & 75 & 80
\end{tabular}

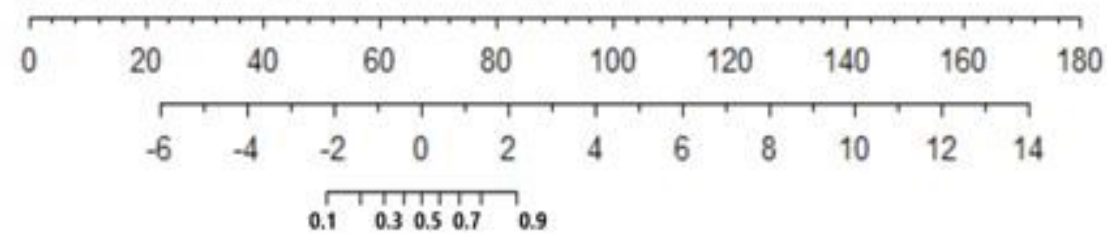

\section{Figure 2}

2A. Nomogram of the prognostic model for predicting mortality in the moderate to severe TBI cohort in this study.

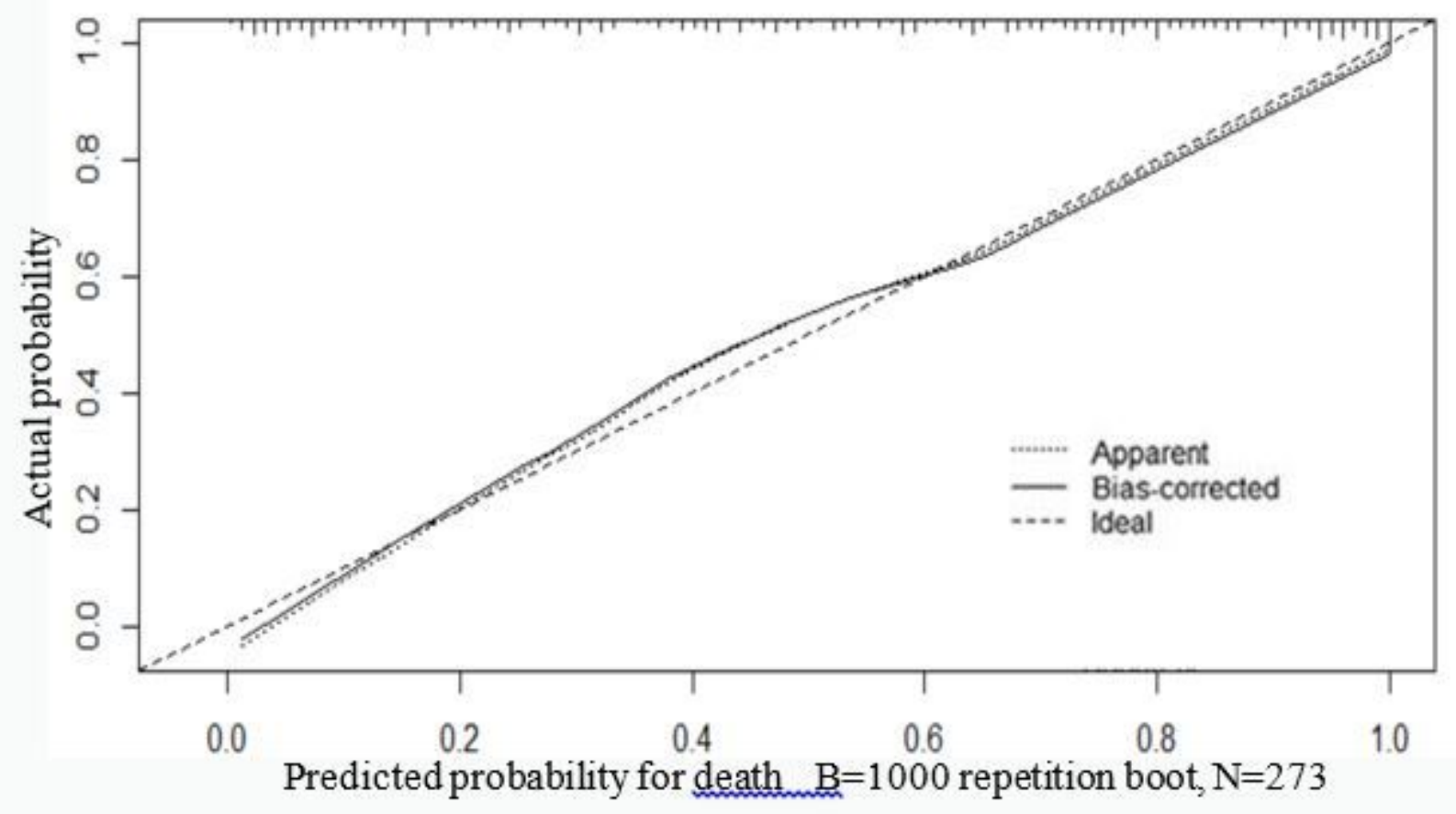

Figure 3 
2B. Calibration plot for predicting mortality in the moderate to severe TBI cohort in this study. 